\title{
SEROTYPING AND ANTIMICROBIAL DRUG RESISTANCE OF SALMONELLA ISOLATED FROM LETTUCE AND HUMAN DIARRHEA SAMPLES IN BURKINA FASO.
}

\author{
Somda Namwin Siourimè ${ }^{1,2}$, Bonkoungou Ouindgueta Juste Isidore ${ }^{2,3}$, Traoré Oumar $^{2,3}$, Bassolé \\ Ismael Henri Nestor ${ }^{3}$, Traoré Yves ${ }^{1}$, Barro Nicolas ${ }^{3}$ and Savadogo Aly ${ }^{{ }^{*}}$
}

${ }^{1}$ Laboratoire de Biochimie et d'Immunologie Appliquée (LABIA). Centre de Recherche en Sciences Biologiques, Alimentaires et Nutritionnelles (CRSBAN). Département de Biochimie-Microbiologie. UFR en Sciences de la vie et de la terre. Ecole Doctorale Sciences et Technologies. Université Ouaga I Pr Joseph KiZerbo, 03 BP 7021 Ouagadougou 03, Burkina Faso. ${ }^{2}$ Laboratoire National de Santé Publique (LNSP), 09 BP 24 Ouagadougou 09, Burkina Faso. ${ }^{3}$ Laboratoire de Biologie Moléculaire d'Epidémiologie et de Surveillance des agents Transmissibles par les Aliments (LaBESTA). Centre de Recherche en Sciences Biologiques, Alimentaires et Nutritionnelles (CRSBAN). Département de Biochimie-Microbiologie. UFR en Sciences de la vie et de la terre. Ecole Doctorale Sciences et Technologies. Université Ouaga I Pr Joseph Ki-Zerbo, 03 BP 7021 Ouagadougou 03, Burkina Faso.

Corresponding author Email: alysavadogo@gmail.com

\begin{abstract}
Background: In Burkina Faso dirty water in particular those of the stoppings and the gutter ones are used for vegetables irrigation in the gardens. The aim of this study was to determine the prevalence and antibiotic susceptibility of Salmonella serotypes from humans and lettuce samples in Burkina Faso.

Materials and Methods: Salmonella strains isolated from patients in 2009 to 2015 and lettuce samples in 2014 in Burkina Faso were serotyped using specific antisera. All strains were subjected to a set of 14 antibiotics to study their antibiogram by using Baeur-Kirby disk diffusion method.

Results: Out of 154 Salmonella isolated, 60 were from human and 94 from lettuce samples. Serotyping revealed four different serotypes and 39\% (60) untypeable strains from human and lettuce (14 and 46 strains). Salmonella serotypes from human and lettuce samples were: Paratyphi A (10\% and 22\%), Paratyphi B (34\% and 8\%), Paratyphi C (14\% and $18 \%$ ) and Typhi (21\% and 1\%). A high resistance of Salmonella Paratyphi B and Salmonella spp to tetracycline were $70 \%$ from human and $35 \%$ from lettuce samples. Multiresistance was observed to tetracycline, chloramphenicol and amoxicillin/clavulanic-acid or ampicillin with Salmonella Paratyphi B 35\% and Salmonella Typhi 33\% from human samples and Salmonella spp 4\% from lettuce samples.

Conclusion: This study showed the diversity of Salmonella serotypes from both clinical and environmental samples and emergence of multiresistant Salmonella to antibiotics in Burkina Faso. A lettuce is a potential source of transmission of Salmonella causing diarrhea among human in Burkina Faso.
\end{abstract}

Keywords: Salmonella serotypes, antimicrobial susceptibility, lettuce, human

List of non-standard Abbreviations :HDB: Hôpital du District de Bogodogo, LNSP: Laboratoire National de Santé Publique,

DSG : District Sanitaire de Gourcy, DSB : District Sanitaire de Boromo

\section{Introduction}

Salmonella is an enteric bacterial pathogen and a major pathogenic bacterium that causes food poisoning. Its routes of infection include contaminated foods and water. Salmonella species are leading causes of acute gastroenteritis in several countries and salmonellosis remains an important public health problem worldwide, particularly in the developing countries (Rotimi et al., 2008). Developing countries are more concerned by a broad range of these diseases among which appears cholera, campylobacteriosis, infections with Escherichia coli, shigellosis, brucellosis, hepatitis A and salmonellosis. In this numerous of foodborne infections, salmonellosis is the most frequent infection with a great number of serotypes and intoxications caused with lethality in 1\% cases (Ao et al., 2015; Assi-Claire, 2000). Among the most foodborne infections with Salmonella, the lettuce takes up a significant place.

In Burkina Faso, rains shortage leads to the practice of the farming irrigated by barrage or waste water. It is the case of the truck farmer production. The dirty water in particular those of the stoppings and the gutter ones are used for the vegetables irrigation. Theses vegetables mainly lettuce are generally contaminated by the enteric bacteria in particular Salmonella from this contaminated water (Traoré et al., 2015). According to Petterson et al. (2010), the consumption of 
the fruit and vegetables constitutes a factor of potential risk of infection by bacteria enteropathogens such as Salmonella and Escherichia coli O157. Cases of food poisoning related to the contaminated vegetable ingestion were identified a little everywhere in the world (Wendel et al., 2009). Among the factors generally implicated in the contamination of vegetables appears the irrigation water (Koffi-Nevry et al., 2011).

Drug resistance among Salmonella strains has emerged worldwide, making antimicrobial susceptibility testing an important role in public health laboratories. Antibacterial agents are often recommended for the treatment of suspected salmonellosis. Patients were not responding to the most available antibiotics of choice. Those practices can enhance the antibiotics resistances genes. It is now generally accepted that the main risk factor for the increase of resistance to pathogenic bacteria is the anarchic use of antibiotics. Previous studies in Burkina Faso showed that Salmonella enterica isolated from meat and several foods is resistant to commonly used antibiotics like amoxicillin/clavulanic-acid, aztreonam, cefalotin, ceftriaxone, cefepim, gentamicin, chloramphenicol, tetracycline, nalidixic-acid and ciprofloxaxin (Bagré et al., 2014; Bsadjo Tchamba et al., 2015).

In this study, we examined lettuce samples from garden and stools samples from diarrheic persons to determine Salmonella. Specifically, the aims of this study were (1) to determine the Salmonella serotypes and antimicrobial resistance of the obtained isolates and (2) to compare the serotypes and resistance profiles to those previously obtained from the lettuce and human.

\section{Materials and methods Study design, population and settings}

A total of 94 Salmonella were isolated from 134 lettuce samples collected in 2014 in the surrounding environments of the dam number 3 of Ouagadougou and the university hospital Yalgagado Ouédraogo, the biggest hospital in Burkina Faso. In addition, 60 Salmonella were isolated from 765 (447 in Ouagadougou, 125 in Boromo and 193 in Gourcy) patients with diarrhea between 2009 and 2015 in three regions in Burkina Faso: -Ouagadougou (Hopital du District de Bogodogo (HDB) and Laboratoire National de Santé Publique (LNSP)), which is the capital city located in the center of Burkina Faso;

-Gourcy (District Sanitaire de Gourcy (DSG))

-and Boromo (District Sanitaire de Boromo (DSB)), which are rural areas located in northern and western parts of the country.

All samples, human and lettuce were analysed at National Public Health Laboratory (LNSP) in Ouagadougou for pathogens isolation and stored for further analysis at $-30^{\circ} \mathrm{C}$.

\section{Microbiological analyses}

The suspected Salmonella samples were placed on Mueller Hinton Agar (Himedia, India) and incubated at $37^{\circ} \mathrm{C}$ for 18-24h. The colonies were subjected to biochemical reactions using Enteric API 20E according to manufactures' instructions (BioMerieux, France) for further confirmation. Serotyping was done by slide agglutination using Salmonella polyvalent A, B, C, T, Vi antisera (Bio-Rad, France) according to the Kauffmann-White classification scheme (Popoff et al., 2004). All isolates were also tested for susceptibility to 14 different antimicrobial agents using the disk diffusion method on Mueller Hinton II agar (Bio-Rad France) following the European Committee on Antimicrobial Susceptibility Instructions (EUCAST) guidelines (EUCAST, 2013). E. coli ATCC 25922 and ATCC 35218 were used as a control. The antimicrobial disks (Himedia, India) used were nalidixic-acid (30 $\mu$ g), ciprofloxacin $(5 \mu \mathrm{g})$, ampicillin $(10 \mu \mathrm{g})$, amoxicillin $(25 \mu \mathrm{g})$ cefotaxime $(30 \mu \mathrm{g})$, imipenem $(10 \mu \mathrm{g})$, tetracycline $(30 \mu \mathrm{g})$, gentamicin $(10 \mu \mathrm{g})$, chloramphenicol $(30 \mu \mathrm{g})$, ceftriaxone $(30 \mu \mathrm{g})$, norfloxacin $(10 \mu \mathrm{g})$, ticarcillin $(75 \mu \mathrm{g})$, amoxicillin/clavulanic-acid $(30 \mu \mathrm{g})$ and trimethoprime/sulfamexazol $(25 \mu \mathrm{g})$. Inhibition diameters of the antibiotics were interpreted according to the EUCAST (EUCAST, 2013). The multiresistant is defined as the resistance to at least three different antibiotics family (Magiorakos et al., 2011). Extended-spectrum $\beta$-lactamases (ESBL) activity was carried out by using amoxicillin/clavulanic-acid against cefotaxime, ceftriaxone.

\section{Results \\ Bacterial isolates from humans and lettuce}

Out of 154 Salmonella isolated, $39 \%$ (60) were from human and $61 \%$ (94) from lettuce samples. Of 60 Salmonella enterica isolates from human, $27 \%$ (16/60) of strains were from rural and $73 \%$ (44/60) from urban clinical samples. This study showed high prevalence of Salmonella from male $57 \%$ than female $43 \%$. Our results showed that $40 \%$ of Salmonella were isolated from patients aged 12-23 months and $27 \%$ of patients aged 0-11 months reported Salmonella (Table 1). 
Somda et al., Afr., J. Infect. Dis. (2017) 11 (2): 24-30

https://doi.org/10.21010/ajid.v11i2.4

Table 1: Salmonella distribution by locality, age and sex

\begin{tabular}{|c|c|c|c|c|c|c|}
\hline Age (months) & & 0 - 11 & $12-23$ & $24-35$ & $36-47$ & $48-59$ \\
\hline \multirow[t]{4}{*}{ Males } & HDB & 2 & 7 & 2 & 0 & 1 \\
\hline & LNSP & 2 & 5 & 1 & 1 & 2 \\
\hline & DSB & 6 & 1 & 1 & 0 & 0 \\
\hline & DSG & 1 & 0 & 1 & 0 & 0 \\
\hline Sous-Total & $\begin{array}{l}33 \\
(56,89 \%)\end{array}$ & 11 & 13 & 5 & 1 & 3 \\
\hline \multirow[t]{4}{*}{ Females } & HDB & 2 & 4 & 4 & 2 & 1 \\
\hline & LNSP & 1 & 3 & 1 & 0 & 1 \\
\hline & DSB & 2 & 2 & 0 & 0 & 0 \\
\hline & DSG & 0 & 2 & 0 & 0 & 0 \\
\hline Sous-Total & $\begin{array}{l}25 \\
(43,11 \%)\end{array}$ & 5 & 11 & 5 & 2 & 2 \\
\hline Total & & $16(27,58 \%)$ & $24(41,4 \%)$ & $10(17,2 \%)$ & $3(5,17 \%)$ & $5(8,62 \%)$ \\
\hline
\end{tabular}

Legend: $\%=$ percentage, HDB= Hopital de District de Bogodogo, LNSP= Laboratoire National de Santé Publique, $\mathrm{DSB}=$ District Sanitaire de Boromo, DSG= District Sanitaire de Gourcy.

\section{Salmonella serotypes}

Of 60 human Salmonella isolates, $77 \%$ (46/60) were serotyped. Globally highest prevalence was observed to serotype Paratyphi B $34 \%$ followed Typhi $20 \%$, Paratyphi C $13 \%$ and Paratyphi A $10 \%$. According to the localities, the highest prevalence was observed with Salmonella serotype Paratyphi B: 3/4, 11/25 and 4/12 from DSG, HDB (Ouagadougou) and DSB respectively and then the serotype Typhi: 6/19, 1/4, 2/12 and 3/25 from LNSP, DSG, DSB and HDB respectively (Table 2). Salmonella spp were identified in $23 \%(14 / 60)$. These isolates were not reacting to antisera used in our study.

Out of 94 Salmonella enterica isolates from lettuce, $51 \%(48 / 94)$ reacted to the antisera used. The highest prevalence was observed to Salmonella serotype Paratyphi A $23 \%$ followed by Paratyphi C $18 \%$, Paratyphi B $8 \%$ and serotype Typhi $1 \%$ (Table 3). Salmonella spp represented $49 \%(46 / 94)$ of the strains did not react to the antisera used.

\section{Antimicrobial susceptibility testing of human isolates}

The Salmonella isolates originating from human were all resistant to fourteen (14) antibiotics. A higher frequency of antimicrobial resistance was observed to tetracycline $55 \%$, ticarcillin $38 \%$, amoxicillin/clavulanic-acid, ampicillin, amoxicillin $36 \%$ and trimethoprime/sulfamexazol $33 \%$. Low frequency of resistance was observed to imipenem $3 \%$, ceftriaxon, cefotaxime $5 \%$, ciprofloxacin, norfloxacin, gentamicin $7 \%$ and nalidixic-acid $10 \%$ (Table 4). From different serotypes tested, the high resistance was observed with tetracycline 14/20, ampicillin, amoxicillin, amoxicillin/clavulanic-acid, ticarcillin 12/20, trimethoprime/sulfamexazol $11 / 20$ and chloramphenicol 10/20 to Salmonella Paratyphi B. Resistance was observed to imipenem 02/20, ceftriaxone, cefotaxime, ciprofloxacin, norfloxacin, nalidixic-acid, and gentamicin 01/20 with Salmonella Paratyphi B. Extended-spectrum $\beta$-lactamases (ESBL) were not observed.

Table 2: Salmonella serotypes distribution by locality

\begin{tabular}{lllllll}
\hline Sites/Serotypes & $\begin{array}{l}\text { S.Paratyphi } \\
\text { A }\end{array}$ & $\begin{array}{l}\text { S.Paratyphi } \\
\text { B }\end{array}$ & $\begin{array}{l}\text { S.Paratyphi } \\
\text { C }\end{array}$ & S.Typhi & Salmonella.spp & TOTAL \\
\hline HDB & $01(04 \%)$ & $11(44 \%)$ & $05(20 \%)$ & $03(12 \%)$ & $05(20 \%)$ & $25(100 \%)$ \\
LNSP & $03(18 \%)$ & $02(12 \%)$ & $01(06 \%)$ & $06(35 \%)$ & $05(29 \%)$ & $17(100 \%)$ \\
DSB & $02(17 \%)$ & $04(33 \%)$ & $02(17 \%)$ & $02(17 \%)$ & $02(17 \%)$ & $12(100 \%)$ \\
DSG & 00 & $03(75 \%)$ & 00 & $01(25 \%)$ & 00 & $04(100 \%)$ \\
TOTAL & $06(10 \%)$ & $20(34 \%)$ & $08(14 \%)$ & $12(21 \%)$ & $12(21 \%)$ & $58(100 \%)$ \\
\hline
\end{tabular}

Legend: $S=$ Salmonella, $00=$ no prevalence, $\%=$ percentage, $\mathrm{HDB}=$ Hopital de District de Bogodogo, LNSP= Laboratoire National de Santé Publique, DSB= District Sanitaire de Boromo, DSG= District Sanitaire de Gourcy. 
Somda et al., Afr., J. Infect. Dis. (2017) 11 (2): 24-30

https://doi.org/10.21010/ajid.v11i2.4

Table 3: Salmonella serotype from lettuce

\begin{tabular}{|l|l|l|l|l|l|l|}
\hline Serotypes & $\begin{array}{l}\text { S.Paratyphi } \\
\text { A }\end{array}$ & $\begin{array}{l}\text { S.Paratyphi } \\
\text { B }\end{array}$ & $\begin{array}{l}\text { S.Paratyphi } \\
\text { C }\end{array}$ & $\begin{array}{l}\text { S.Typhi } \\
\text { Salmonella.spp }\end{array}$ & Total \\
\hline Prevalence & $22(23 \%)$ & $08(09 \%)$ & $17(18 \%)$ & $01(01 \%)$ & $46(49 \%)$ & $94(100 \%)$ \\
\hline
\end{tabular}

Legend: $S=$ Salmonella, \%=percentage.+

Table 4: Frequency of antimicrobial resistance in Salmonella isolates from human

\begin{tabular}{lllllll}
\hline Antibiotiques & \multicolumn{5}{c}{ Salmonella serotypes } \\
& S.Paratyphi & S.Paratyphi & S. Paratyphi & S. Typhi & Salmonella.spp & Total \\
& A & $\mathrm{B}$ & $\mathrm{C}$ & $\mathrm{N}=12$ & $\mathrm{~N}=12$ & $\mathrm{~N}=58$ \\
& $\mathrm{~N}=06$ & $\mathrm{~N}=20$ & $\mathrm{~N}=08$ & & & $21(36 \%)$ \\
AMP & $02(33 \%)$ & $12(60 \%)$ & 00 & $05(42 \%)$ & $02(17 \%)$ & $21(36 \%)$ \\
AMX & $02(33 \%)$ & $12(60 \%)$ & 00 & $05(42 \%)$ & $02(17 \%)$ & $21(36 \%)$ \\
AMC & $02(33 \%)$ & $12(60 \%)$ & 00 & $05(42 \%)$ & $02(17 \%)$ & $3(5 \%)$ \\
CTR & 00 & $01(05 \%)$ & 00 & 00 & $02(17 \%)$ & $2(3 \%)$ \\
IMI & 00 & $02(10 \%)$ & 00 & 00 & 00 & $3(5 \%)$ \\
CTX & 00 & $01(05 \%)$ & 00 & 00 & $02(17 \%)$ & $22(38 \%)$ \\
TI & $02(33 \%)$ & $12(60 \%)$ & 00 & $06(50 \%)$ & $02(17 \%)$ & $4(7 \%)$ \\
GEN & $01(17 \%)$ & $01(05 \%)$ & 00 & 00 & $02(17 \%)$ & $19(33 \%)$ \\
COT & $02(33 \%)$ & $11(55 \%)$ & 00 & $04(33 \%)$ & $02(17 \%)$ & $6(10 \%)$ \\
NA & $02(33 \%)$ & $01(05 \%)$ & 00 & $01(08 \%)$ & $02(17 \%)$ & $4(07 \%)$ \\
CIP & $01(17 \%)$ & $01(05 \%)$ & 00 & 00 & $02(17 \%)$ & $4(07 \%)$ \\
NX & $01(17 \%)$ & $01(05 \%)$ & 00 & 00 & $02(17 \%)$ & $17(29 \%)$ \\
C & $01(17 \%)$ & $10(50 \%)$ & 00 & $05(42 \%)$ & $01(08 \%)$ & $32(55 \%)$ \\
TE & $02(33 \%)$ & $14(70 \%)$ & $03(38 \%)$ & $06(50 \%)$ & $07(58 \%)$ & \\
\hline
\end{tabular}

Legend: $\mathrm{AMP}=$ ampicillin, $\mathrm{AMX}=$ amoxicillin, $\mathrm{AMC}=$ amoxicillin/cluvulanic-acid, $\mathrm{CRO}=$ ceftriaxone, $\mathrm{CT} \mathrm{X}=$ cefotaxime, $\mathrm{NX}=$ norfloxacin, $\mathrm{COT}=$ trimithoprime/sulfamexazol, $\mathrm{C}=$ chloramphenicol, $\mathrm{CIP}=$ ciprofloxacin, $\mathrm{GEN}=$ gentamicin, $\mathrm{IMI}=$ imipenem, $\mathrm{NA}=$ nalidixicacid, $\mathrm{TE}=$ tetracycline, $\mathrm{TC}=$ ticarcillin, $\%=$ percentage,$S=$ Salmonella, $\mathrm{N}=$ number.

\section{Antimicrobial susceptibility testing of lettuce isolates.}

All 94 lettuce isolates were susceptible to imipenem, gentamicin, ceftriaxone, cefotaxime and ciprofloxacin. We observed a low antimicrobial resistance to tetracycline $22 \%$, amoxicillin/clavulanic-acid, amoxicillin, ampicillin, chloramphenicol, nalidixic-acid and trimethoprime/sulfamexazol respectively $7 \%, 6 \%, 5 \%, 4 \%, 3 \%$, and $2 \%$. The resistance was observed to tetracycline, amoxicillin/clavulanic-acid, amoxicillin, ampicillin, ticarcillin and trimethoprime/sulfamexazol, 01/17 with Salmonella Paratyphi C (Table 5).

Table 5: Frequency of antimicrobial resistance in Salmonella isolates from lettuce

\begin{tabular}{lllllll}
\hline Antibiotiques & \multicolumn{5}{c}{ Salmonella sérotypes } \\
& S.Paratyphi A & S. Paratyphi B & S.Paratyphi C & S.Typhi & S.spp & Total \\
& N=22 & N=09 & N=17 & N=01 & N=46 & N=94 \\
\hline AMP & 00 & 00 & $01(06 \%)$ & 00 & $04(09 \%)$ & $5(05 \%)$ \\
AMX & 00 & 00 & $01(06 \%)$ & 00 & $05(11 \%)$ & $6(06 \%)$ \\
AMC & 00 & 00 & $01(06 \%)$ & 00 & $06(13 \%)$ & $7(07 \%)$ \\
CTR & 00 & 00 & 00 & 00 & 00 & 00 \\
IMI & 00 & 00 & 00 & 00 & 00 & 00 \\
CTX & 00 & 00 & 00 & 00 & 00 & 00 \\
TI & 00 & 00 & $01(06 \%)$ & 00 & $02(04 \%)$ & $3(03 \%)$ \\
GEN & 00 & 00 & 00 & 00 & 00 & 00 \\
COT & 00 & 00 & $01(06 \%)$ & 00 & $01(02 \%)$ & $2(02 \%)$ \\
NA & 00 & 00 & 00 & 00 & $03(07 \%)$ & $3(03 \%)$ \\
CIP & 00 & 00 & 00 & 00 & 00 & 00 \\
NX & 00 & 00 & 00 & 00 & $01(02 \%)$ & $1(01 \%)$ \\
C & 00 & 00 & 00 & 00 & $04(09 \%)$ & $4(04 \%)$ \\
TE & $03(14 \%)$ & $01(13 \%)$ & $01(06 \%)$ & 00 & $16(35 \%)$ & $21(22 \%)$ \\
\hline
\end{tabular}




\section{Somda et al., Afr., J. Infect. Dis. (2017) 11 (2): 24-30 \\ https://doi.org/10.21010/ajid.v11i2.4}

Legend: $\mathrm{AMP}=$ ampicillin, $\mathrm{AMX}=$ amoxicillin, $\mathrm{AMC}=$ amoxicillin/cluvulanic-acid, $\mathrm{CRO}=$ ceftriaxone, $\mathrm{CTX}=$ cefotaxime, $\mathrm{NX}=$ norfloxacin, $\mathrm{COT}=$ trimithoprime/sulfamexazol, $\mathrm{C}=$ chloramphenicol, $\mathrm{CIP}=$ ciprofloxacin, $\mathrm{GEN}=$ gentamicin, $\mathrm{IMI}=$ imipenem, $\mathrm{NA}=$ nalidixicacid, $\mathrm{TE}=$ tetracycline, $\mathrm{TC}=$ ticarcillin, $\%=$ percentage,$S=$ Salmonella, $\mathrm{N}=$ number

\section{Multi-drugs resistance}

This study revealed multidrugs resistance (resistance of three or more antibiotics with differents families) with Salmonella Paratyphi B 07/20, Salmonella Typhi 04/12, Salmonella Paratyphi A 01/06 and Salmonella spp 02/12 from the clinical Salmonella isolates. However, Salmonella isolated from lettuce showed multidrugs resistance with Salmonella spp 02/46 (4 \%). In the Hospital, multidrugs resistance observed with Salmonella Paratyphi B from DSB 03/04, DSG02/03, LNSP 01/02 and HDB 04/11 followed Salmonella Typhi from DSB, LNSP 03/06 and HDB 01/03.

\section{Discussion}

Salmonellosis is one of the major bacterial diseases transmitted from food. In this study, we investigated the distribution of Salmonella serotypes between human and lettuce isolates and highlight the consumption of lettuce as potential source of transmission of Salmonella causing diarrhea among human in Burkina Faso.

In Ouagadougou, people use generally waste water for vegetable irrigation. The high number of Salmonella strains isolated from lettuce was expected. Indeed, Salmonella is reported to be an environmentally persistent pathogen capable of surviving and proliferating in diverse environments (Winfield and Groisman, 2003).

In addition, our study site was a high risk of pathogens spread in environment. Vegetable farmers in our study locations depend largely on contaminated waste water from dam to irrigate their produce, while also using untreated animal manure as sources of nutrient supply to vegetables. Due to the vicinity, waste water from university hospital Yalgado Ouedraogo, the biggest hospital in the country is released into a canal which flows nearby the dam.

The distribution of serotypes of Salmonella from lettuce samples comprised Salmonella Typhi 1\%, Salmonella Paratyphi 50\% and Salmonella spp (untypeable) 49\%. Salmonella Paratyphi has long been reported as a common cause of foodborne gastroenteritis (Hur et al., 2012). Also, the presence of Salmonella Typhi from lettuce is an indication of feacal contamination. Our finding supports the well-documented role of the presence of Salmonella in waste water and animals feces in environmental contamination in Burkina Faso as in some others developing countries (Kagambèga et al., 2013; Traoré et al., 2015).

The distribution of serotypes of Salmonella from human samples comprised Salmonella Typhi 21\%, Salmonella Paratyphi 58\% and Salmonella spp (untypeable) 21\%. Salmonella Typhi was the second most common serotype isolated after Salmonella Paratyphi B. The high prevalence of Salmonella Typhi among isolates reveals that this pathogen still constitutes a significant public health importance in the country, therefore, appropriate control measures, such as vaccination and food safety measurements, need to be put in place. Recent study shown that Salmonella serotype Typhi and Paratyphi B were the most serotypes incriminated in diarrheal infections in Burkina Faso (Timbiné, 2014).

All serotypes Typhi, Paratyphi A, B and C were found in both human and lettuce samples. As reported in Burkina Faso and in the others parts of the world, Salmonella from fresh vegetables (carrots, radish, lettuce and parsley) play important role in foodborne disease (Afema et al., 2016; Islam et al., 2004; Koffi-Nevry et al., 2012; Traoré et al., 2015). We speculate that lettuce as well as fresh vegetables consumption without food safety measurement is a high risk of foodborne disease such as Salmonella different serotypes isolated but further research is needed to explore more this hypothesis by using modern techniques.

In addition, as the reservoir of typhoid and non-typhoid serotypes being water and animals and their products (OMS, 2O13), shows that in Burkina Faso infections of Salmonella may be related to both sanitation and food hygiene.

The majority of the human isolates were resistant to tetracycline, ticarcillin, ampicillin, amoxicillin, and amoxicillin/cluvulanic-acid. Similar results have been reported in Burkina Faso and Nigeria (Bawa et al., 2016; Fashae et al., 2010). Multidrug resistance to these old and commonly used antimicrobials is a public health problem and could facilitate usage of fluoroquinolones and third-generation cephalosporins for empiric treatment (Yang et al., 2013). Salmonella Paratyphi B was the most resistant of the serotypes isolated from human isolates to urban and rural sites and exhibited resistance to tetracycline, ticarcillin, ampicillin, amoxicillin, amoxicillin/cluvulanic-acid and trimethoprime/sulfamexazol. Similar results have been reported in Burkina Faso (Bawa et al., 2016). In our study, it was noted the emergence of strains resistant to imipenem $10 \%$, ceftriaxone, cefotaxime, ciprofloxacin, norfloxacin, nalidixic-acid, and gentamicin (5\% to each antibiotic) with Salmonella Paratyphi B. This situation might be explain by the fact that in developing countries, populations are used to self-medication and use proscribed drugs sold on the street because of their low standard of living and education. These practices increase the phenomenon of bacteria resistance. 
These observations call for regulation of antibiotics usage in Burkina Faso to avoid the spread of resistance to antimicrobials.

Our results showed that the great majority of Salmonella isolates from lettuce were more commonly susceptible to ciprofloxacin, ceftriaxone, cefotaxime, imipenem and gentamicin. However low resistances were observed to tetracyclin, ampicillin, amoxicillin, amoxicillin/cluvulanic-acid and chloramphenicol. These results are consistent with those found in Burkina Faso in 2015 on isolated Salmonella strains in the environment (Traoré et al., 2015). A study on Salmonella isolated from animal feces in Ouagadougou was resistant to one or more tested antimicrobials (Kagambega et al., 2013). Others studies in Burkina Faso showed that Salmonella enterica isolated from meat and several foods is resistant to commonly used antibiotics like amoxicillin/clavulanic-acid, aztreonam, cefalotin, ceftriaxone, cefepim, gentamicin, chloramphenicol, tetracycline, nalidixic-acid and ciprofloxaxin (Bagré et al., 2014; Bsadjo Tchamba et al., 2015).

\section{Conclusion}

To conclude, this study reports the presence of Salmonella similar serotypes in lettuce samples from irrigation sites and human isolates in Burkina Faso. The Consumption of lettuce without proper disinfection represents a serious public health risk. It also shows the emergence of multiresistant bacteria with clinical serotypes. The resistance of Salmonella serotypes to quinolones highlights the need for the establishment of a network and continuous monitoring of antibiotic resistance.

\section{Acknowledgements}

The authors gratefully acknowledge the Laboratoire National de Santé Publique/Burkina Faso and the Laboratoire de Biochimie Immunologie Appliquée (LaBIA)/Centre de Recherche en Sciences Biologiques, Alimentaires et Nutritionnelles (CRSBAN), Ecole Doctorale Sciences et Technologies, UFR-SVT, Université Ouaga I Pr Joseph KIZERBO, Burkina Faso.

\section{Authors' contributions}

SNS carried out the sampling and strains isolation, serotyping and their antibiotics susceptibility and drafted the manuscript, BOJ, OT, BIHN, TY, BN and SA supervised the sampling and strains isolation, serotyping, antibiotics susceptibility and participated in writing the manuscript. All authors read and approved the final version of the manuscript.

\section{References}

1. Afema, J.A., Byarugaba, D.K., Shah, D.H., Atukwase, E., Nambi, M., Sischo, W.M. (2016). Potential Sources and Transmission of Salmonella and Antimicrobial Resistance in Kampala, Uganda. PLoS ONE 11:e0152130. doi:10.1371/journal.pone.0152130.

2. Ao, T.T., Feasey, N.A., Gordon, M.A., Keddy, K.H., Angulo, F.J. and Crump, J.A. (2015). Global burden of invasive non typhoidal Salmonella disease, 2010. Emerg. Infect. Dis., 21: 941-949.

3. Assi-Claire, B.J. (2000). Allergies et intoxication, les intoxications alimentaires. EUFIC http//www.eufic.org/gb/safe/food.htm. Accessed 07 June 2016.

4. Bagré, T.S., Kagambèga, A., Bawa, I.H, Bsadjo Tchamba, G., Dembélé, R., Zongo, C., Savadogo, A., Aggad, H., Traoré, A.S. and Barro, N. (2014). Antibiotic susceptibility of Escherichia coli and Salmonella strains isolated from raw and curds milk consumed in Ouagadougou and Ziniaré, Burkina Faso. Afr. J. Microbiol. Res., 8: 10121016.

5. Bawa, H.I., Dembélé, R., Bsadjo Tchamba, G., Bonkoungou, O.I.J., Bougoudogo, F., Traoré, S.A. and Barro, N. (2016). Antimicrobial susceptibility of Salmonella serotypes isolated from human in West-Africa (Burkina Faso, Mali and Niger). Europ. J. Pharm. Med. Res., 3: 117-122.

6. Bsadjo Tchamba, G., Bawa, I.H., Nzouankeu, A., Bagré, T.S, Traoré, A.S. and Barro, N. (2015). Isolation, characterization and antibiotic susceptibility of Escherichia coli and Salmonella spp. isolated from local beverages (bissap, gnamakoudji) sold in Ouagadougou, Burkina Faso. Int. J. Biosc., 6: 112-119.

7. European Committee on Antimicrobial Susceptibility Testing (EUCAST). (2013). Breakpoint tables for interpretation of MICs and zone diameters. http://www.eucast.org. Accessed 10 May 2016.

8. Fashae, K., Ogunsola, F., Aarestrup, F.M. and Hendriksen, R.S. (2010). Antimicrobial susceptibility and serovars of Salmonella from chickens and humans in Ibadan, Nigeria. J. Infect. Dev. Ctries. 4: 484-494. 


\section{Somda et al., Afr., J. Infect. Dis. (2017) 11 (2): 24-30}

https://doi.org/10.21010/ajid.v11i2.4

9. Hur, J. and Jawale, C. (2012). Antimicrobial resistance of Salmonella isolated from animals: a review. Food. Res. Int., 45: 819-830.

10. Islam, M., Morgan, J., Doyle, M.P., Phatak, S.C., Millner, P. and Jang, X. (2004). Persistence of Salmonella enterica serovar Typhimurium on lettuce and parsley and in soils on which they were grown in fields treated with contaminated water. Foodborne Pathog. Dis., 1: 27-35.

11. Kagambèga, A., Lienemann, T., Aulu, L., Traoré, A.S., Barro. N., Siitonen, A. and Haukka, K. (2013). Prevalence and characterization of Salmonella enterica from the feces of cattle, poultry, swine and hedgehogs in Burkina Faso and their comparison to human Salmonella isolates. BMC. Microbiol., 13: 2-9.

12. Koffi-Nevry, R., Assi-Claire, B.J., Koussemon, M., Wognin, A.S. and Coulibaly, N. (2011). Potential Enterobacteria risk factors associated with contamination of lettuce (Lactuca sativa) grown in the peri urban area of Abidjan (Côte d'Ivoire). Int. J. Biol. Chem. Sci., 5: 279-290.

13. Koffi-Nevry, R., Assi-Clair, B.J., Assemand, F.E., Wognin, A.S. and Koussemon, M. (2012). Origine des témoins de contamination fécale de l'eau d'arrosage de la laitue (Lactuca sativa) cultivée dans la zone péri urbaine d'Abidjan. J. Appl. Biosc., 52: 3669-3675.

14. Magiorakos, A.P, Srinivasan, A., Carey, R.B., Carmeli, Y., Falagas, M.E., Giske, C.G., Harbarth, S., Hindler, J.F., Kahlmeter, G., Olsson-Liljequist, B., Paterson, D.L., Rice, L.B., Stelling, J., Struelens, M.J., Vatopoulos, A., Weber, J.T. and Monnet, D.L. (2011). Multidrug resistant, extensively drug-resistant and pandrug-resistant bacteria: an international expert proposal for interim standard definitions for acquired resistance. Clin. Microbiol. Inf. http://dx.doi.org/10.1111/j.1469-0691.2011.03570.x.

15. Organisation Mondiale de la Santé (OMS). (2013). Infections à Salmonella (non typhiques). Aide-mémoire $\mathrm{N}^{\circ} 139$. http://www.who.int/mediacentre/factsheets/fs139/fr/. Accessed 03 June 2016.

16. Petterson, S.R., Ashbolt, N.J. and Sharma, A. (2010). Microbial risks from wastewater irrigation of salad crops: a screening-level risk assessment. J. Food. Sci., 75: 283-290.

17. Popoff, M.Y., Bockemuhl, J. and Gheesling, L.L. (2004). Supplement 2002 (no. 46) to the Kauffmann-White scheme. Res. Microbiol., 155: 568-570.

18. Rotimi, V.O., Jamal, W., Pal, T., Sonnevend, A., Dimitrov, T.S. and Albert, M.J. (2008). Emergence of multidrugresistant Salmonella spp. and isolates with reduced susceptibility to ciprofloxacin in Kuwait and the United Arab Emirates. Diagn. Microbiol. Infect. Dis., 60: 71-78.

19. Timbiné, L.G. (2014). Epidémiologie moléculaire de la résistance aux antibiotiques des bactéries entériques isolées en Afrique de l'Ouest (Burkina Faso, Mali, Sénégal). Thèse de Doctorat, Biologie et Pathologie Humaine, Université Cheikh Anta Diop de Dakar, Sénégal.

20. Traoré, O., Nyholm, O., Siitonen, A., Bonkoungou, O.J.I., Traoré, S.A., Barro, N. and Haukka, K. (2015). Prevalence and diversity of Salmonella enterica in water, fish and lettuce in Ouagadougou, Burkina Faso. BMC Microbiol., 15: 151-157.

21. Wendel, A.M., Johnson, D.H., Sharapov, U., Grant, J., Archer, J.R. and Monson, T. (2009). Multistate outbreak of Escherichia coli $\mathrm{O} 157: \mathrm{H} 7$ infection associated with consumption of packaged spinach, August-September 2006: the Wisconsin investigation. Clin. Infect. Dis., 48: 1079-1086.

22. Winfield, M.D. and Groisman, E.A. (2003). Role of non-host environments in the lifestyles of Salmonella and Escherichia coli. Appl. Environ. Microb., 69: 3687-3694.

23. Yang, H., Chen, G., Zhu, Y., Lui, Y., Cheng, J., Hu, L., Ye, Y. and Li. J. (2013). Surveillance of antibiomicrobial susceptibility Patterns among Shigella species isolated in china during the 7-year period of $2005-2011$. http://dx.doi.org/10.3343/alm.2013.33.2.111. Accessed 17 June 2016. 